\title{
Integrating complex hydrogeological and geotechnical models - a discussion of methods and issues
}

\author{
G. Fagerlund SRK Consulting (Canada) Inc., Canada \\ M. Royle Schlumberger Ltd., Canada
}

J. Scibek SRK Consulting (Canada) Inc., Canada

\begin{abstract}
Prediction of pore pressure data used in complex 3D geotechnical slope stability modelling often runs into problems associated with dissimilar model domains, grids, nodal density, etc. This is often due to the larger scale hydrogeological model being restricted to the use of laterally extensive layers to represent the site lithology, whereas the geotechnical models often use a cubic or tetrahedral convex blocking method for model construction. Hydrogeological model platforms do not always allow the modeller to reproduce the geology (especially if steeply dipping, over turned, or pinching out) or the slope details to the level of detail expected for the stability modelling.

To alleviate this problem, the use of regular sized elements in horizontal to moderately variable layers/slices is described. The model geometry is not new, but presented here as a means of solving some common problems encountered in pit design modelling. The resulting efficiencies in model construction, ability to modify the geology and pit wall design during the modelling process, and more accurately simulate a complex 3D problem in the hydrogeological model simulation are discussed. Methods for simulating drainage tunnels, drill hole fans, and horizontal drains using 'discrete elements' are presented. Additionally, the problems encountered with using larger scale (mine scale) models to determine boundary conditions for the smaller, pit wall scale models are discussed, with several methods for dealing with this reviewed.

This paper describes methods used to construct a FEFLOW ${ }^{\circledR}$ (DHI-WASY GmbH, 2012) finite element model of the West Wall 3DEC ${ }^{\circledR}$ (Itasca, 2013) stability analysis for the Ok Tedi mine life extension (MLE) that overcame some of these issues. However, the methods used are not limited to FEFLOW ${ }^{\circledR}$ or even Finite Element models, and are used with other codes that the hydrogeological modellers are familiar with. The paper does not presume to be a comprehensive examination of the methods and issues, rather to provide useful tips and discussion points for the slope stability modelling audience. As such, recognised limitations of the methods are included, and the authors invite readers to use this as a means to initiate further consideration of the modelling issues involved in the increasingly complex stability analyses taking place these days.
\end{abstract}

\section{Introduction}

This paper presents a case study of multidisciplinary effort to develop a 3D slope model of a large open pit mine for the purpose of predicting pit wall slope stability during pit expansion. It provides a discussion of some of the common issues, and a number of techniques that are used in various groundwater model codes to work past these. The paper is not intended to be a detailed treatise of modelling techniques, but instead serve as a dialogue paper for prompting discussion of methods, issues, and limitations.

One of the key issues encountered during slope design evaluations is the integration of the work of mine planners, geotechnical engineers, and hydrogeologists, as concurrent changes to the project resource and project economics dictate frequent, and sometimes very significant, changes to the pit geometry and sequencing. These changes are often difficult to assess as they require costly (in fees and additional time) 
redesign of the evaluation models. As discussed in the open panel discussion held at the 2011 Slope Stability Conference in Vancouver, the project assessment schedule does not usually allow for sufficient iteration in the design process to balance the needs and requirements of these three task groups, often leading to undesirable assumptions or limitations in the appraisal.

Recognising that the assessment schedules and the necessity for concurrent assessment are not likely to change, a primary goal of the modelling process for any of the slope design team will be the fast integration of changes made to design, inputs, etc. To this end, flexibility in model design is a vital design criterion of the models.

Common Issues faced by the hydrogeological modellers when attempting to integrate with the mine planners and geotechnical engineers are:

- Variability in domain size.

- Data limitations within and outside the pit area, but within necessary model boundaries.

- Complex geology (unable to duplicate using standard layered modelling approach).

- Scale issues (bench and multi bench scale).

- Changes in mine geometry related to sequencing.

- Inflexibility in model design (to allow for mid-modelling changes to pit geometry).

- Changes in hydraulic properties as pit progresses.

This paper deals primarily with aspects of the hydrogeological modelling team's deliverables and the requirements of the stability assessment of the preferred slope/mine design. The model used to illustrate some of the methods for working around the problems discussed above was designed by SRK Consulting Canada (SRK-C) to integrate as easily as possible with the stability analysis carried out by SRK Consulting Australia (SRK-A). The objective of this combined work was to verify the design and sequencing completed by Ok Tedi Mining Limited (OTML) for the West Wall Mine Life Extension (MLE) design.

\section{Example model: Ok Tedi - West Wall Mine Life Extension}

The Ok Tedi copper-gold mine, owned by OTML, is located in Papua New Guinea, in the Star Mountains region of the Western Province. The mine location is shown in Figure 1. Ok Tedi's current annual copper and gold production is 160,000 tonnes and 540,000 ounces gold respectively. OTML proposes to extend the mine life and produce an estimated 90 million tonnes of ore containing close to 700,000 tonnes of copper and 2.3 million ounces of gold. The extension will deepen the base of the excavation by approximately $200 \mathrm{~m}$ below the current pit base.

The Ok Tedi West Wall MLE groundwater model was completed to support the pit slope design verification work. Input requirements for the 3D geotechnical modelling, carried out using the 3DEC ${ }^{\circledR}$ code (developed by Itasca International Inc.), included detailed 3D pore pressure distributions at various stages of the MLE cut back schedule, rather than simple hydrostatic water table positions.

The West Wall numerical groundwater model was designed to provide a tool that would:

- Match the 3DEC ${ }^{\circledR}$ geotechnical model geometry.

- Reproduce a complex geology (including units that are truncated or pinched out).

- Allow for easy adaptation to accommodate potential changes to site geology, pit excavation design, etc. during the process of the slope stability analyses.

- Simulate multiple design options of dewatering tunnels and drains.

- Provide reasonable 3D pressure inputs to the $3 D E C^{\circledR}$ slope stability model. 
- Have the ability to integrate changes in geology and geotechnical models as efficiently as possible.
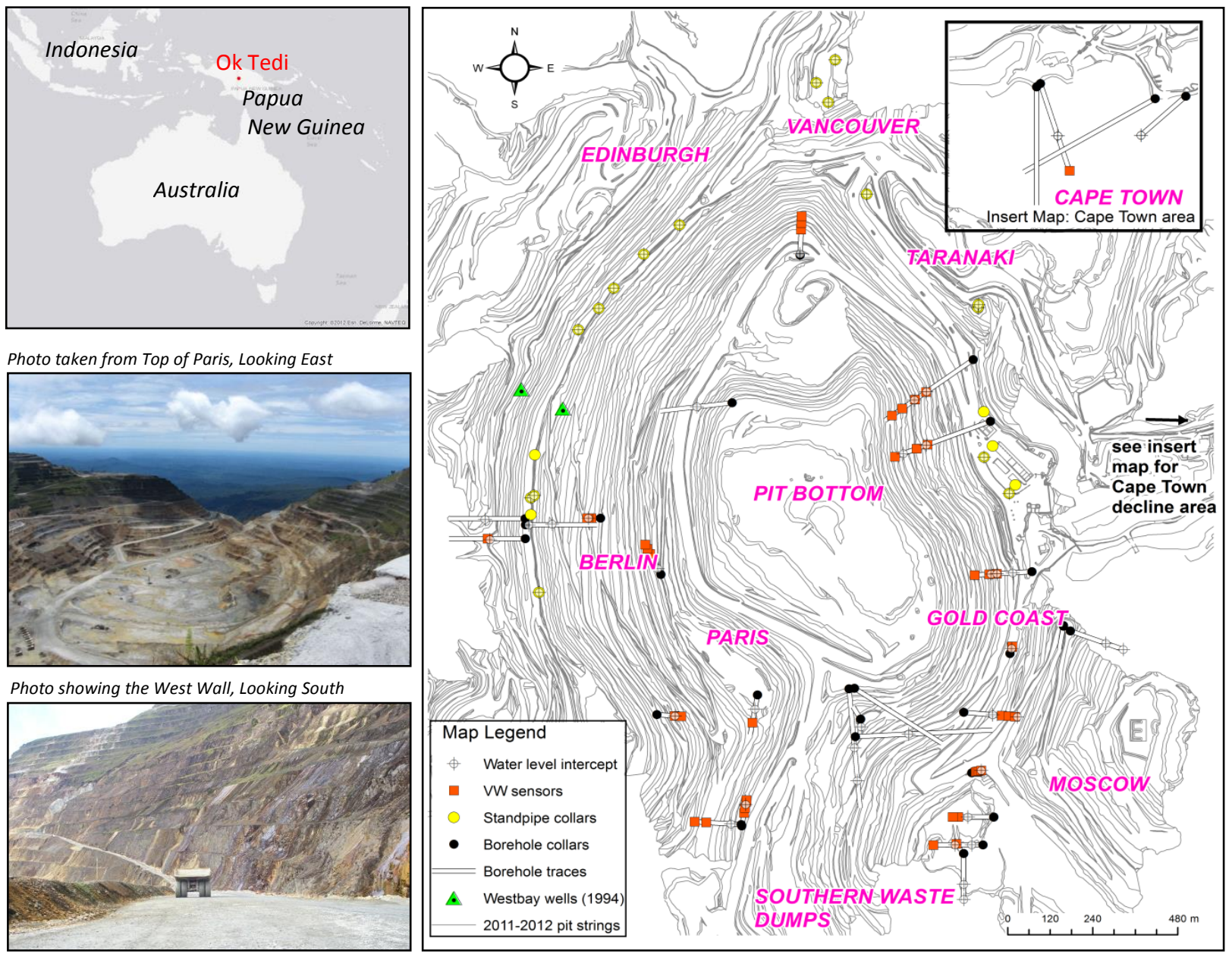

\section{Figure 1 Site location and pit map showing available data points}

\subsection{Variability in geotechnical and hydrogeological domain size}

The domains of geotechnical and hydrogeological models rarely match. Slope stability analyses typically focus on the pit and immediate periphery, which only covers a small portion of the site in comparison to domain that affects the hydrogeological system. To assess the effects of a large open pit, the hydrogeological domain is delineated by the surface and/or groundwater catchment, sometimes spanning multiple catchments, in order to properly incorporate the physical aspects influencing the system. The model domain has direct implications on the calibration of the model. Where a groundwater model can be constructed to match the natural catchment(s), the relationship between recharge rates and base flows (input versus output) and the predicted mass balance are better constrained, resulting in more realistic simulations.

Model boundaries must be located at a sufficient distance to avoid boundary effects (artificially imposed limits on the modelled groundwater system response). The boundary effects occur, for example, if the dewatering caused by a pit reaches the model edge. If this limit is a 'no flow' boundary (i.e. a groundwater divide at a topographical peak), the groundwater table will be predicted to drop faster than it would; if the limit is a constant head boundary (i.e. a large river that acts as constant source of water), the water table will equilibrate with the constant supply of water and dewatering would not appear to be as effective. These will lead to either overly optimistic or pessimistic pore pressure predictions for the stability analysis.

The selection of the model domain is also dependant on data limitations outside the pit. As the data are usually unavailable, simplifications and assumptions need to be made at an early stage, such that alternative techniques can be used to minimise the domain extents. In FEFLOW ${ }^{\circledR}$, it is possible to use what 
are called 'transfer head' boundaries. In simple terms, these boundaries use a retardation factor to virtually simulate the model boundary at a greater 'distance' than is represented by the 'physical' model domain. Whenever possible, the full domain size, with natural groundwater divides, should be utilised. If smaller size is still preferred/required, it is still recommended to design the model to be larger than the geotechnical model in case the geotechnical model size increases at mid-process.

The Ok Tedi West Wall groundwater model proved to be difficult to design along the natural catchment boundaries. The pit is located at high elevation (2,000 masl), close to the peak of a mountain; therefore, a natural groundwater divide is assumed to exist very close to the slope under assessment. The ideal domain would have had to match the course of the closest rivers and would have spread over three large surface water catchments over an area of $110 \mathrm{~km}^{2}$. Almost no data would have been available for the geology and hydraulic parameters on a large part of the model extent. Thus the decision was made to build the model domain smaller than the actual groundwater catchment. To facilitate the integration to the 3DEC ${ }^{\circledR}$ geotechnical model, the groundwater model domain was selected to match what was used by the geotechnical modellers and transfer head boundaries were used to compensate for the smaller size of the domain. Hydrogeological details for the north, south, and eastern portions of the pit were accounted for in the mine scale model and transferred as boundary conditions to the wall scale model.

\subsection{Methods for simulating complex (hydro) geology}

Both lithology and major structures will have a strong effect on the hydrogeological properties of the pit slope and surrounding rock mass. As the understanding of the geology, geotechnical conditions, and groundwater often advanced in parallel, the groundwater model has to be built before the geology model is finalised, often requiring modifications to the model at mid-process based on significant changes in the geological conceptualisation. It is, therefore, crucial that the groundwater model reproduces the complex geology, but has the ability to cope with changes to the geological model throughout the assessment process.

The geotechnical modeller may need to simulate a high level of detail in the stability model, which is difficult to implement right at the start for standard groundwater model designs. As Hammah and Curran (2009) explain:
"A model that starts off complex - has many inputs, assumptions and aspects - actually obscures understanding. When too many details are included before the behaviour of the model is appreciated, interactions among its components will not be clearly apparent. Such a model becomes little more than a 'black box'. (...) In the face of large uncertainties, ill posed questions, and limited resources, simple, easy to use, modelling tools are most practical for mining geomechanics."

For example simulating the pore pressure distribution at the bench scale is feasible, but will invariably lead to time consuming mesh construction, high numbers of nodes, and long computing time. The solution is to start off with the most simple case (interbench scale) and then gradually increase the complexity of the model (bench scale) if needed. Again, using a finite element model with regular sized mesh, such as what has been implemented for Ok Tedi can increase the flexibility to make these modification at later stages.

The geological setting at Ok Tedi is complex, and this complexity was determined to be critical to the stability analysis of the West Wall. The Ok Tedi Mine rock mass comprises a marine succession of sedimentary rocks, on the axis of a WNW-ESE trending anticline. Acidic intrusives penetrated the sedimentary succession causing localised metamorphism and brecciation. The area is structurally influenced by a series of large scale folds and thrust faults developed during interaction between the Australian and Pacific Plates. These structural influences have caused predominantly WNW-ESE trending of major rock types. The area has also observed intense Quaternary uplift and erosion. 
The major rock types within the Ok Tedi Mine surrounds are (Figure 2):

- Sydney Monzodiorite: medium to coarse grained igneous intrusive, contains mostly waste grade.

- Fubilan Monzonite Porphyry: this porphyritic, acid intrusive is the major ore type at Ok Tedi and hosts the economic mineralisation.

- Pnyang Formation: comprising mudstone with thin sandy horizons, may be up to $1,000 \mathrm{~m}$ thick.

- Darai Limestone: up to 1,500 m thick to the north of the mine, often cavernous (karst).

- leru Formation: comprising siltstone and minor sandstone, may be up to 1,500 m thick, sometimes calcareous.

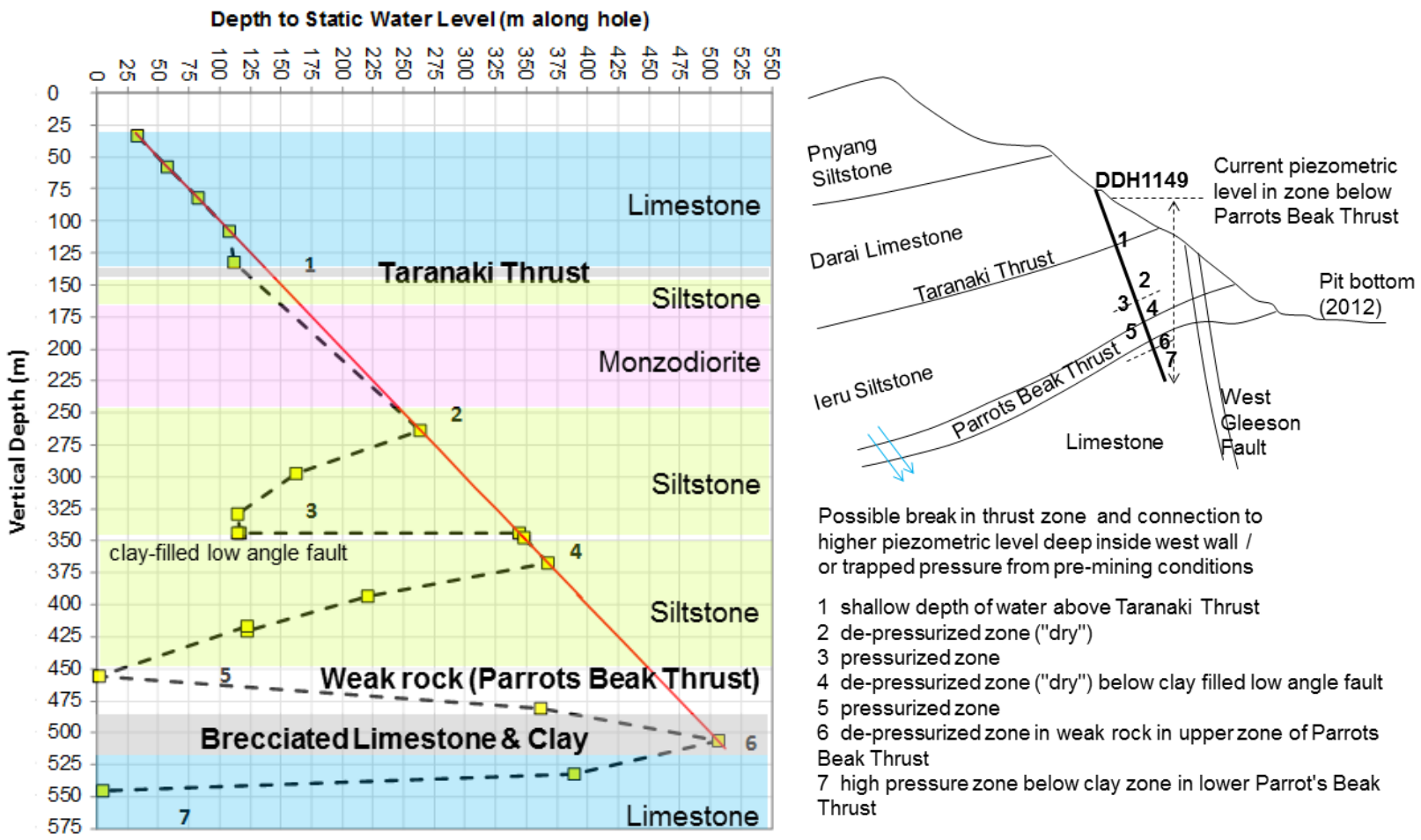

Figure 2 DDH1149: Piezometric levels and geological profile

Skarns have developed at the interface between the intrusive and sedimentary formations and generally host economic mineralisation. High permeability structures have developed where these sulphide and magnetite rich skarns have formed at the interface between the intrusives and the limestone. These were deemed to be significant in the assessment of pore pressures and so needed to be accommodated in the model design.

The West Wall fault zone dips steeply $\left(70\right.$ to $\left.80^{\circ}\right)$ to the east in the west wall of the pit. The zone varies from 100 to $300 \mathrm{~m}$ wide in an E-W direction and extends some $1.5 \mathrm{~km}$ along the west wall of the pit. This area has been termed the West Wall fault zone, and associated with faults referred to as the West and East Gleeson's Faults. The intersection of this major zone with zones of weakness due to the presence of low-angled thrusts (Parrot's Beak, Taranaki and Basal faults; generally dipping to the west and east)and/or bedding planes has caused areas of highly fractured and brecciated siltstones and limestone's of low rock mass quality. The importance of this fault zone, both geotechnically and hydro geologically, is its impact on the ground conditions within the pit and its extensive distribution at surface and depth on the West Wall. The gouge observed in the Gleeson's faults could represent a significant barrier to groundwater flow. No other fault zones of such significance have been recognised in the mine area.

How does this translate to the groundwater model? One of the first challenges was to design a model that faithfully represented the geometry of the hydrogeological units and the West Wall fault zone. A severe 
limitation with essentially all hydrogeological models is that they are only quasi three dimensional, based on layers rather than fully 3D shapes or solids. Because of this limitation, pinched out layers are difficult to reproduce using most (all) modelling platform(s). It can be done in some codes, but requires manual processing tricks that are time consuming, are prone to human error, and increases the difficulty to audit the model at later stages. Furthermore; this method has a high potential to slow down computing processes because it generally goes in pair with a large augmentation of model nodes. To overcome this issue, a different approach was taken that emphasied the flexibility for simulating complex geology, as well as variations in slope design, without being constrained by the mesh itself. Instead of using the classic finite element layer approach, a regular mesh utilising elements of identical size, both horizontally and vertically, was used. The resulting model geometry is shown on Figure 3.

The construction method is different from a standard finite element model approach, in that layers are equally distributed at arbitrary elevations and do not correspond to topography or geological surfaces. The model is built with 3D prisms of approximately homogeneous size over the entire domain onto which the lithological/structural parameters are assigned to reproduce a complex geology model. This approach can be compared to the regimented grid of a finite difference model (i.e. MODFLOW model). This design allows for additional flexibility in the model, particularly to simulate various pit walls in the same model mesh, and to reproduce pinched, folded, and over turned geological units.

To fill the mesh with the geology and pit geometry characteristics, the modeller uses the 3D geology model and the pit geometry at the various stages to create selections of nodes or elements that will identify each geological unit and/or structural feature by tagging them with a 3D GIS or 3D mining software (i.e. Vulcan). These so called 'selections', which correspond to simple text files that list the nodes or elements ID, can be imported to FEFLOW ${ }^{\circledR}$ and then used to quickly build up the geology model.

In this approach, as the grid extends above the 'ground surface', it must be noted that the FEFLOW ${ }^{\circledR}$ code $^{\circ}$ cannot delete or deactivate elements located above the simulated ground surface. These elements belong to a virtual unit that was designated as 'Air', whose only function was to transmit recharge from the top slice, down to the geological units. It was assigned an extremely high vertical $\mathrm{K}$ and extremely low horizontal K, so that it has virtually no influence on the groundwater system other than conveying recharge. Figure 4 shows the final design of the model and 3D distribution of hydraulic properties. Other codes may be able to avoid this requirement by either deactivating the 'Air' elements or applying recharge to the nodes/cells desired, so has to be assessed on a case by case basis.

\subsection{Changing slope design, excavation sequencing, and pushback scale}

Slope stability analyses often require multiple iterations to take into account pit wall sectors that are found to be below the design Factor of Safety or probability of failure. Modification to slopes, level of details, and stages are frequent and it is important that groundwater modelling does not delay the geotechnical simulations. The Ok Tedi model was designed to be flexible and to allow quick changes on the fly. Once the workflow is available to allow for assigning attributes to the appropriate elements, it is fairly easy and fast to modify them, plug the new selections to the model, and re-arrange the hydraulic properties. The model doesn't have to be completely rebuilt, which would be the case using a standard approach. 


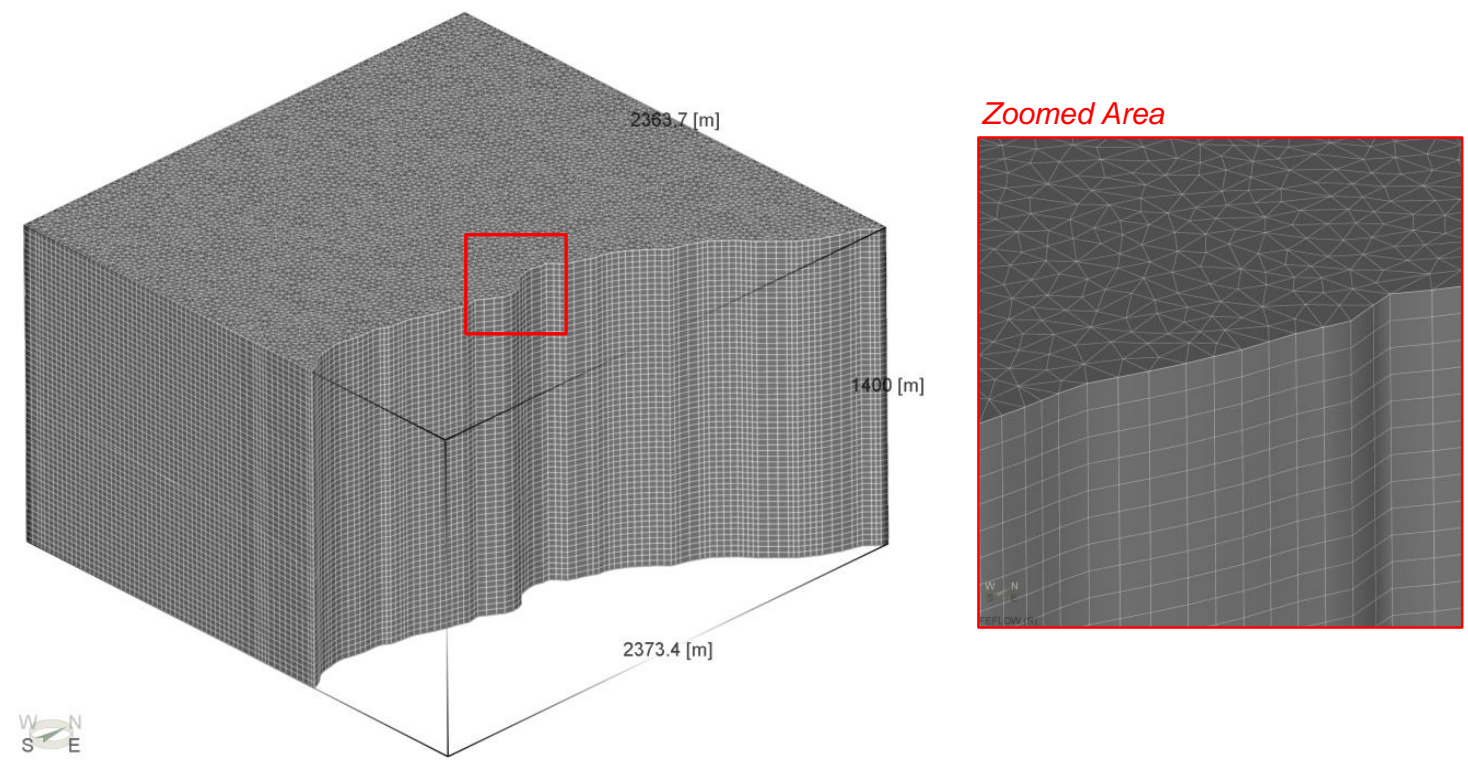

Figure 3 West Wall model mesh and layers

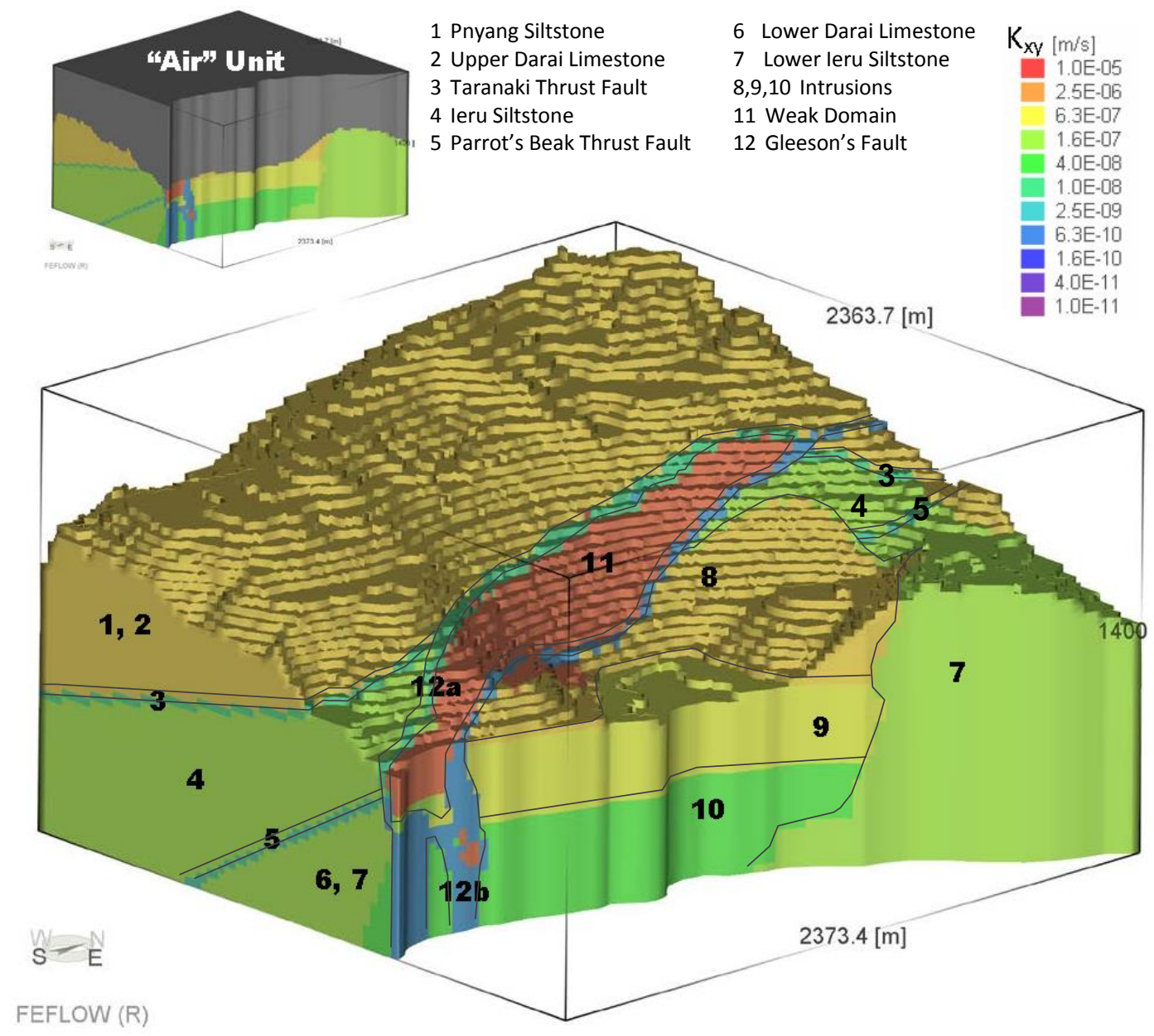

Figure 4 Spatial distribution of $K$ in model 


\subsection{Changes in hydraulic properties as pit progresses}

In a paper on hydromechanical coupling and pit slope movements Sullivan said that

"Pore water controls the deformation of porous media and in turn the deformation of porous media affects pore fluid pressures and flows, mainly by altering hydraulic conductivity and storage. This is a two way process and is a fundamental aspect of the dynamic interaction that affects the deformation of pit slopes and the groundwater contained within them, including rainfall runoff. This process is termed 'hydromechanical coupling'. The effect of deformation on hydraulic properties of the rock mass can be quite substantial. Wyllie and Mah (2004) reported and 18 fold increase in hydraulic conductivity associated with a $170 \mathrm{~m}$ deep excavation in granite for the Three Gorges Dam project in China." (...)

"In open pit mining there are also two other factors to account for that are not part of the natural environment; firstly the disturbance due to blasting for excavation, which results in a 'fractured rock aquifer' parallel to the pit walls, and secondly because of the deformations that occur due to unloading there is a change in hydraulic conductivity and storage usually increase in a zone surrounding the open pit, but including the blasting induced fractured zone." Sullivan (2007).

Transient changes to the hydraulic properties of the rock mass have not been implemented in the Ok Tedi model; the properties remained fixed. However it is possible to include transient K or S values, for example distributed along the relaxation zone. Additionally, as new data become available, the extent of this relaxation zone can easily be modified.

\subsection{Active depressurisation}

"In mining, we are usually restricted to one of five techniques for depressurisation of pit slopes natural drainage, horizontal drains, pumps, wells, drainage adits, unloading." Sullivan (2007).

In Feflow ${ }^{\circledR}$, preferential flow paths, such as fractures, drains, boreholes and mine voids, can be simulated using 'Discrete Feature Elements', where flow is calculated using either Darcy's Law, Hagen-Poiseuille cubic law, or Mannings equations. The characteristics of the depressurisation drains or dewatering tunnel (geometry, length, diameters, spacing, etc.) can be changed on the fly to test the sensitivity of the depressurisation system. Horizontal drains traces can be modelled precisely, but there is no need to. A rough approximation is normally more than adequate for inputs to the geotechnical model; however, if higher precision is required, it is a simple process to refine the mesh locally within the area of interest with the model used for this assessment. Based on the estimated unloading impact distribution, unloading can also be incorporated by assigning to selected elements an increased $\mathrm{K}$ values linked to simulation time. This was not carried out in the current modelling as geomechanical unloading effects have not been modelled, and as in high $\mathrm{K}$ rock masses, unloading is unlikely to play as significant a role.

\subsection{Ok Tedi groundwater model predictions}

Two kinds of simulations were conducted: passive depressurisation (simple gravity seepage to pit face) of the pit throughout the planned excavation sequence and enhanced slope depressurisation methods (e.g. surfaced drilled horizontal drains and an underground drainage gallery with and without drains holes drilled from the gallery). With the large number of elements within the model, variations of the enhanced depressurisation scenarios were easily accommodated.

Figure 5 illustrates the results of the simulations related to enhanced slope depressurisation. The drains are assumed to be a $50 \mathrm{~mm}$ diameter and a length of about 250 to $300 \mathrm{~m}$. The drainage galleries are assumed to be $5 \mathrm{~m}$ in diameter. Discretisation of drains and tunnel are seen to be coarse (lines are not straight) in the illustration, but that has minimal to no effect on the predictions. 


\subsection{Integration to $3 \mathrm{DEC} \circledast$}

The FEFLOW ${ }^{\circledR}$ pore pressure was converted to $3 \mathrm{DEC}^{\circledR}$ format. This task simply required a change of format between two different data files as the geometries of both $3 \mathrm{DEC}^{\circledR}$ and $\mathrm{FEFLOW}^{\circledR}$ models are virtually identical. Because the two models were built with the same geology and pit geometry, the transfer was very simple and there was no need to make limiting assumptions on how the predicted pore pressure distribution would fit into the geotechnical model. This is a common problem, leading to complex issues on extrapolating pore pressures between significantly dissimilar model grids, especially in regions of complex, small scale geology such as faults and lithology boundaries. This forcing of data to fit dissimilar models grids is something that intuitively could pose a problem in stability assessments, and will be addressed in future work using the current model design method in comparison to more traditional model construction.

From a geotechnical and hydrogeological modelling perspective, the observed artesian pressure under the Parrot's Beak Fault proved to be of concern relative to the stability analysis modelling results. It is, however, unconfirmed at this stage if the high pressures are a result of a residual pressure from pre-mining conditions, or sourced from a conductive structure in the Parrot's Beak Fault deep inside the West Wall. Additional testing is planned to determine which mechanism is responsible for the high pressures observed; however, due to project timelines this work was not available at the time of the modelling assessment.

Consequently, it was decided to provide to the geotechnical modellers pore pressure that considered the high pressures to be residual from pre-mining conditions. In such case, it could be assumed that by the time the slope would reach the depth where high pressures have been observed, a dewatering tunnel or a network of horizontal drains would have been able to depressurise the confined (compartmentalised) portion of the rock mass.

If the high pressure was due to a conductive structure, simulating such scenario meant that a constant supply of water to the deeper unit would have to be included somehow without any real understanding on what might be the source and paths. Instead of building an hypothetical groundwater model, it was decided with the geotechnical group that the sensitivity of the $3 D E C^{\circledR}$ model to the high pressures observed below Parrot's Beak could be tested with a pore pressure grid that was increased artificially using a customised FISH routine that selected the nodes located below the Parrot's Beak and added a constant pressure value. This scenario would be used to help decision makers in deciding the priorities for upcoming field programs and importance of further testing focused on understanding on these deep pressures. 
$3 D$ view with perspective
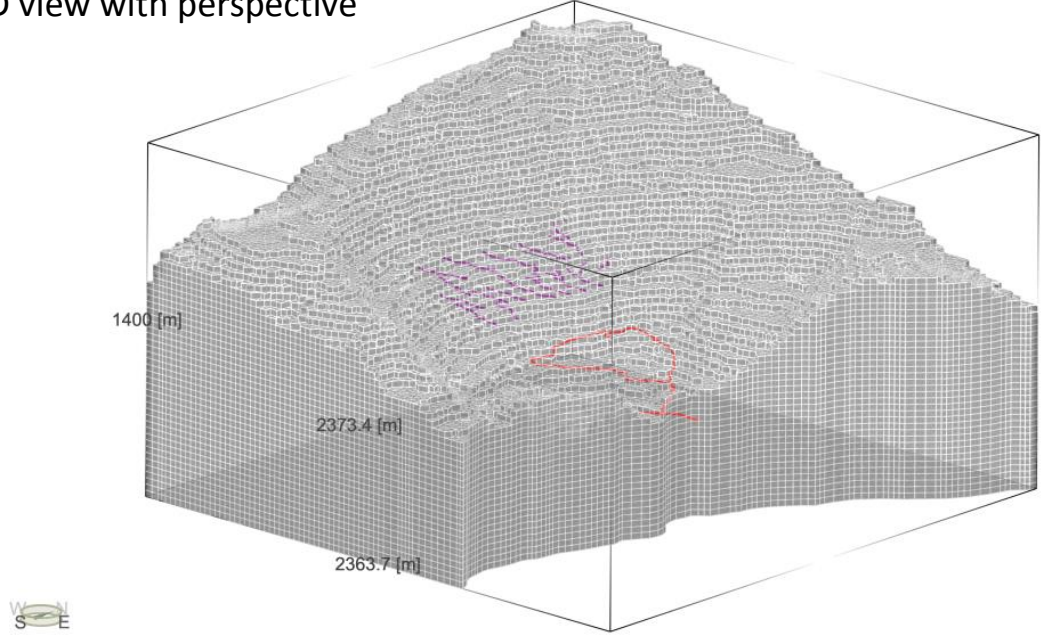

FEFLOW (R)

$3 D$ view from above

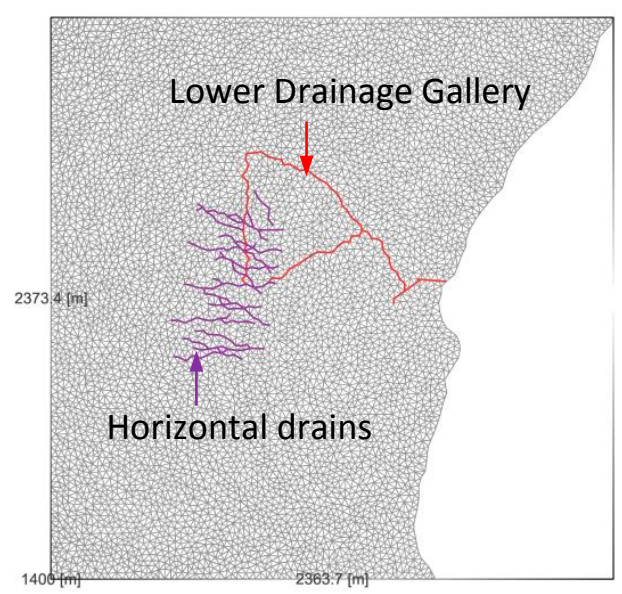

2D slice view

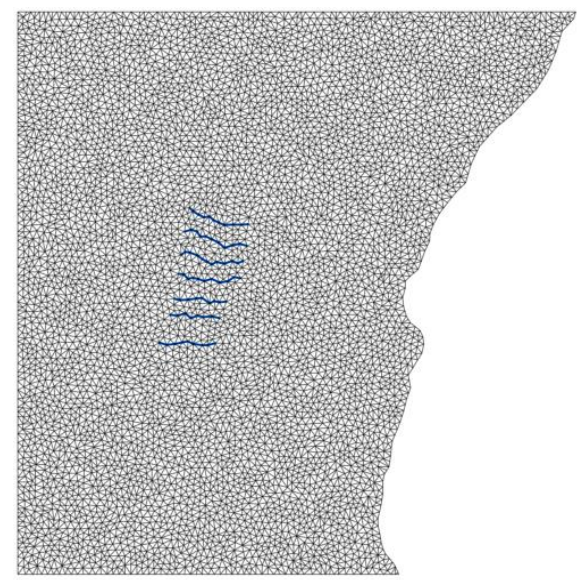

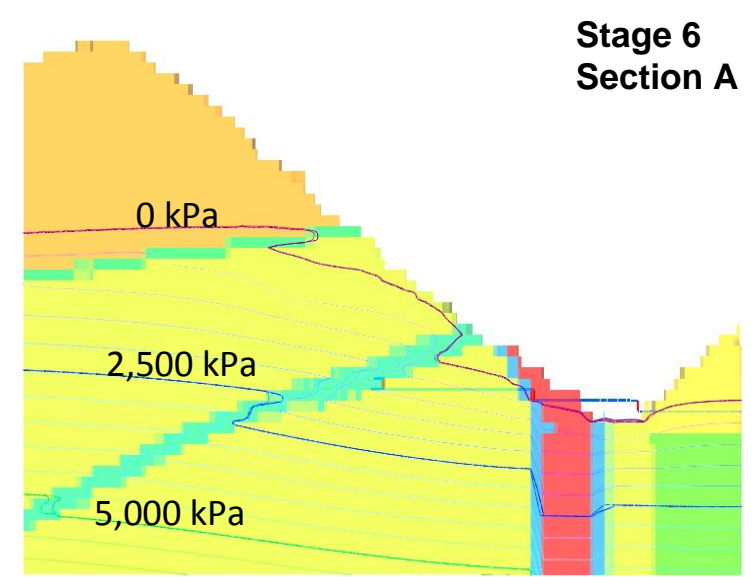

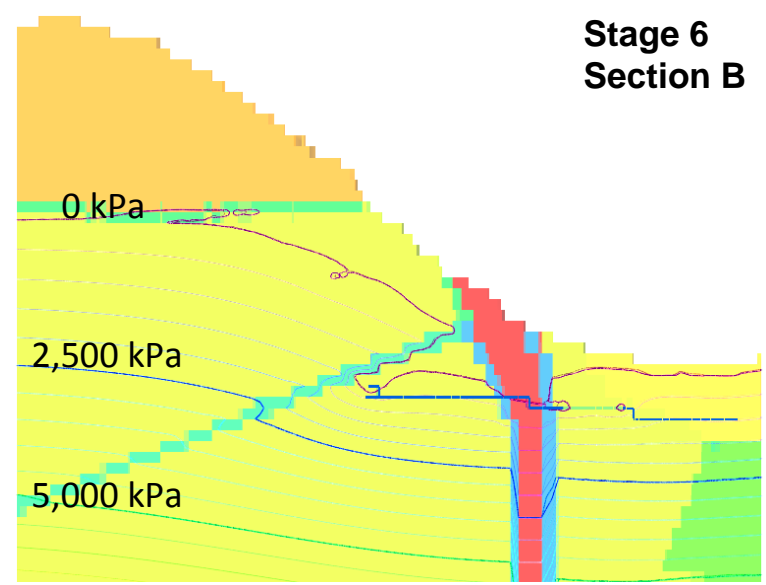

Figure 5 Enhanced slope depressurisation predictions 


\section{Conclusions}

The continuously evolving geological and hydrogeological conceptual model in structurally complex terrains increases the difficulty to develop concurrent slope stability models and groundwater model inputs. A level of uncertainty will always exist and the role of the geotechnical and groundwater modellers is to represent, with a minimum of iterations, the most likely representative system, and to understand what the sensitive parameters are for the problem being solved. Constant re-working of numerical models is time intensive and can seriously affect budget.

Between the slope stability and groundwater models, spatial extent and accuracy (discretisation) may vary. Recent monitoring data may become available in the mid-process that imply major modifications to the conceptual model and/or modify the mine plan and the sequencing scenarios. It is, therefore, crucial that the groundwater model is designed with a primary focus on flexibility to adapt these changes. The faster/easier it is to process these changes (e.g. when the slope is modified after the first iteration of simulated pore pressure that indicates untenable instability), the better it will be for the analyses and the project budgets.

The methods used to construct the FEFLOW ${ }^{\circledR}$ hydrogeological model for the Ok Tedi MLE West Wall stability analysis are examples of what can be achieved to overcome some of these issues. However, the methods used are not limited to FEFLOW ${ }^{\circledR}$ or even finite element models, and could be used with other codes that the hydrogeological modellers are familiar with.

Nowadays, slope stability analyses are

"solved by task forces composed of 'relative strangers', who represent a set of diverse professional skills. Executive and managers in this system will function as coordinators between the various transient work teams. They will be skilled in the understanding the jargon of the different groups of specialists, and they will communicate across groups, translating and interpreting the language of another." Toffler (1984).

We hope that this paper provides to the 'relative strangers' that work together on the verification of pit slope design some understanding on the issues encountered by groundwater modellers that will improve the communication between the groups.

\section{Acknowledgement}

We acknowledge the generous assistance from the OTML geotechnical engineering group in producing this paper, notably Dr Norbert Baczynski and Simon Thomas, Jason Elemunop and Monica Koek, practical 3DEC ${ }^{\circledR}$ modelling integration advice from Dr Michael Coulthard (M.A. Coulthard \& Associates Pty Ltd), and our colleagues lan de Bruyn and Jayanathan Mylvaganam in the SRK-Perth geotechnical group (SRK Consulting (Australasia) Pty Ltd).

\section{References}

DHI-WASY GmbH (2012) FEFLOW, http://www.feflow.info/about.html.

Hammah, R.E. and Curran, J.H. (2009) It is Better to be Approximately Right than Precisely Wrong: Why Simple Models Work in Mining Geomechanics, 43rd US Rock Mechanics Symposium and 4th U.S.-Canada Rock Mechanics Symposium, Asheville, USA.

Itasca Inc. (2013) 3DEC, http://itascacg.com/software/3dec.

Sullivan, T.D. (2007) Hydromechanical Coupling and Pit Slope Movements, in Proceedings International Symposium on Rock Slope Stability in Open Pit Mining and Civil Engineering (Slope07), Y. Potvin (ed), 12-14 September 2007, Perth, Australia, Australian Centre for Geomechanics, Perth, pp. 3-43.

Toffler, A. (1984) Future Shock, Turtleback Books, 576 p.

Wyllie, D.C. and Mah, C.W. (2004) Rock Slope Engineering Civil and Mining, CRC Press, 4th edition. 
Intergrating complex hydrogeology and geotechnical models - a discussion of G.Fagerlund et al. methods and issues 